\title{
¿Qué le pasó a Monterrey? Análisis de una crisis urbana de inseguridad a través del duelo colectivo
}

\author{
Ana Gabriela Sánchez Santana y David Pérez Esparza
}

\section{Introducción}

La ciudad de Monterrey está localizada en el estado mexicano de Nuevo León, donde viven poco más de 4.6 millones de habitantes, el octavo estado más poblado de México. De éstos, 2.3 millones de personas, $62.2 \%$ hombres y $37.8 \%$ mujeres se encuentran económicamente activos (INEGI, 2010). Sin embargo, las condiciones de vida para estos casi cinco millones de personas no han sido fáciles: el $93 \%$ de sus 64,000 kilómetros cuadrados está en zona árida con escasas precipitaciones y altas temperaturas. A pesar de las adversidades que le supone su entorno, el siglo 20 significó para la Zona Metropolitana de Monterrey $(\mathrm{ZMM})^{1}-\mathrm{y}$ en general para el estado de Nuevo León, ${ }^{2}$ una etapa de consolidación económica y social poco vista en las urbes de México y América Latina. De manera particular, el estado ha ocupado el tercer lugar nacional tanto en disponibilidad de capital como en productividad laboral, siendo esta última, la de mayor crecimiento del país. Adicionalmente, ha sido el segundo lugar nacional en otros indicadores clave, como en presencia de banca comercial; eficiencia de recaudación fiscal; y de manera destacada, en competitividad económica (IMCO, 2010). Como consecuencia de lo anterior, la aportación de Nuevo León a la economía mexicana es del 7.5\% del Producto Interno Bruto (PIB). Per cápita, la riqueza es $82.6 \%$ mayor al promedio nacional y con ello es uno de los mercados subnacionales más fuertes de México (El Economista, 2010). Gracias a todo ello, algunos habitantes de Monterrey se crearon una imagen de ciudad pionera en la administración de sus recursos y en la industrialización de sus procesos. Una ciudad de alto crecimiento académico y cultural, con gran actividad científica y tecnológica; una zona dinámica, preparada y competitiva (IDB, 2009). A pesar de lo anterior, un proceso inverso comenzó a surgir a partir de los primeros años del siglo 21. Para el 2004, esta posición de liderazgo y estabilidad se 
vio vulnerada. Nuevo León comenzó a enfrentar un problema que nunca antes había experimentado: un crecimiento cuantitativo-y cualitativoen materia de incidencia delictiva. Esta situación provocó que, en unos cuantos años, la ZMM dejara de ser uno de los lugares más prósperos y seguros de toda América Latina, para convertirse en una ciudad con una crisis moral y de inseguridad que logró impactar a múltiples áreas de la vida cotidiana ${ }^{3}$. Tomando en cuenta esta rápida transición, este artículo parte de la idea de que el análisis de una ciudad-región (en referencia a la $\mathrm{ZMM}$ ) que experimenta un crecimiento en incidencia delictiva, puede comprenderse a través de uno de los fenómenos estudiados por la psicología: el duelo. La hipótesis aquí presentada es que ambos fenómenos son, en el fondo, lo mismo: un shock traumático doloroso, casi siempre inesperado e indeseado, y compuesto por etapas más o menos definidas. Para la realización de este análisis se tomaron como base los datos oficiales de incidencia delictiva; notas periodísticas; interpretaciones teóricas en el contexto de la política pública, la ciencia política, la sociología y la psicología; y en general, reflexiones conceptuales de los asuntos públicos.

\section{Caracterización de Monterrey y diagnóstico de la incidencia delictiva: entender la realidad a través de los hechos}

Tan pronto finalizó la Revolución Mexicana de 1917, Nuevo León comenzó a despuntar como una entidad emprendedora donde la actividad empresarial fungía como la amalgama de una sociedad en crecimiento, y la cultura de trabajo arduo era su máximo exponente. La abundante historia económica industrial de Monterrey es fundamental para comprender dicha dinámica.

A lo largo del siglo 20, la economía de Nuevo León se consolidó con la creación de clústeres industriales automotrices, de electrodomésticos y de productos electrónicos de consumo manufacturados en los parques industriales a las afueras de Monterrey, mismos que se vieron favorecidos con la expansión de la infraestructura urbana ${ }^{4}$. Para su época, y considerando las condiciones en que vivía el país, los productos de Nuevo León tenían mayor valor agregado que los de sus contrapartes de otros estados, hecho que fomentó una autopercepción de superioridad técnica e industrial.

Desde aquella época, Monterrey entró en un proceso de industrialización caracterizado por la creación de un mercado de trabajo regional propio, lo que tuvo como consecuencia natural un crecimiento poblacional importante durante las siguientes décadas, provocando un fuerte proceso de metropolización (Hernández, 2006). La ciudad logró un liderazgo con- 
tinental y además, fue capaz de construir infraestructura y servicios de calidad de la mano de una sociedad con valores compartidos que tenían como resultado vivir en un entorno seguro, con la confianza que inspiraba el ideal de progreso, desarrollo, paz y tranquilidad (Pussetto, García, \& Pérez Esparza, 2008).

Lo anterior contribuyó al incremento del orgullo de la población sobre los logros locales, sobre todo vis-à-vis la crítica frecuente al centralismo ejercido desde la capital, la Ciudad de México. El fortalecimiento de esta identidad consolidó en el imaginario colectivo regiomontano ${ }^{5}$ la idea de pertenecer al estado que en lo individual aportaba más recursos a la federación y el que menos recibía de ésta. Dicha situación, aunque considerada injusta, hacía sentir a su ciudadano parte del verdadero motor del país, un fenómeno similar a lo que ocurre con otras ciudades no-capitales en el mundo ${ }^{6}$ en ese enfrentamiento simbólico con la ciudad capital por el control del dinero, el poder político y la toma de decisiones de poder.

Además de lo económico y de los valores empresariales, Monterrey llegó a ser considerada como una de las ciudades más seguras del país (ICESI, 2009). De hecho, a pesar de ser una de las poblaciones más grandes, la gente que habitaba en la ZMM señalaba con frecuencia que vivir en ella le daba lo mejor de dos mundos. Les permitía vivir en una ciudad próspera con trabajo, riqueza y opciones comerciales y de entretenimiento; y al mismo tiempo, tener las ventajas de habitar en un lugar tan seguro como el entorno rural donde existía una percepción generalizada de que "todos cumplen las reglas porque se conocen".

Así, cuando el país comenzó a experimentar las primeras manifestaciones de violencia organizada al inicio del siglo 21, (especialmente en Chihuahua, Guerrero, Sinaloa o Michoacán), la mayor parte de los regiomontanos no se vieron cercanos a ese proceso, según lo demuestran la Encuesta Nacional sobre Inseguridad y la Encuesta Nacional de Victimización y Percepción sobre Seguridad Pública ${ }^{7}$. Una hipótesis es que los regiomontanos parecen haber supuesto que las ventajas económicas de su ciudad la harían impenetrable al embate de las organizaciones delictivas, o que ante una contingencia, tendría una fortaleza institucional y un capital social suficiente para contener al crimen. ${ }^{8}$ Dicho razonamiento resultó ser una falacia.

La evidencia revela que los delitos del fuero común 9 habrían alcanzado su máximo en 2001 (la mayoría de ellos siendo delitos menores) y a partir de entonces, comenzaron un descenso hasta 2006, tal como puede observarse en la Figura 1. A partir de 2007, el crecimiento es sustancial hasta llegar a los altos niveles experimentados en 2008, ahora con delitos de mayor impacto y violencia, nunca antes vistos en Monterrey, como secuestro y extorsión. 


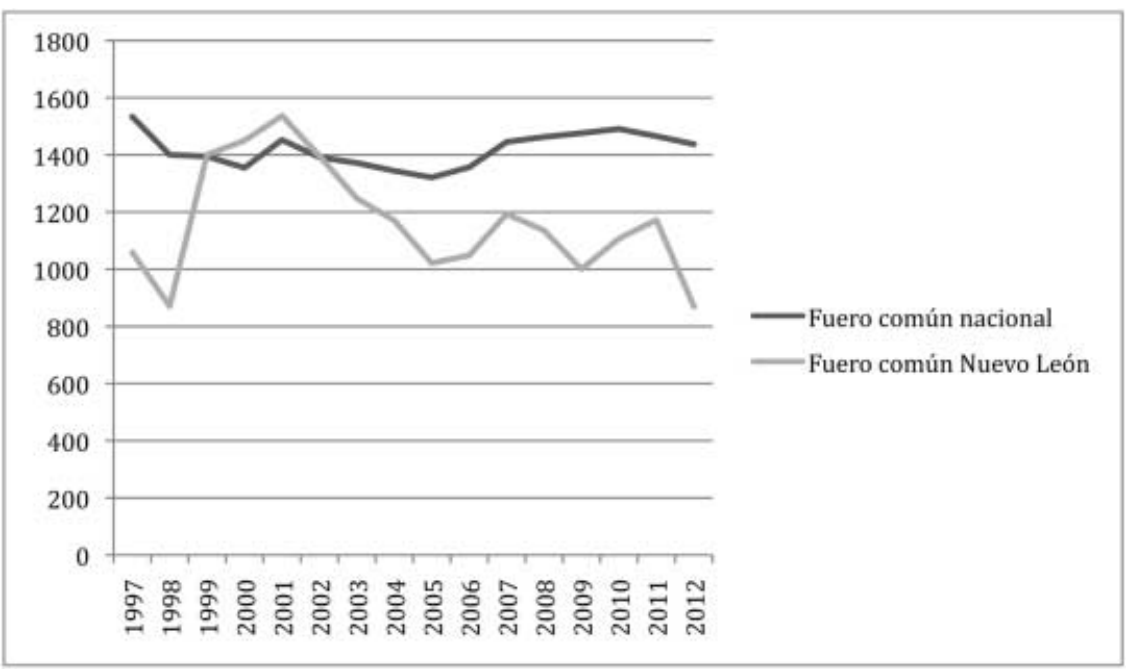

Figura 1 - Denuncias de delitos del fuero común a nivel nacional y en NL por cada 100 mil habitantes

Fuente: Sistema Nacional de Seguridad Pública

Los delitos del fuero federal ${ }^{10}$ se mantuvieron sin cambios significativos entre 1997 y 2003, tal como que se observa en la Figura 2. Sin embargo, a partir del 2004, este tipo de delitos-los más evidentes y de mayor impacto social-crecieron de forma importante hasta el 2007. Aunque luego

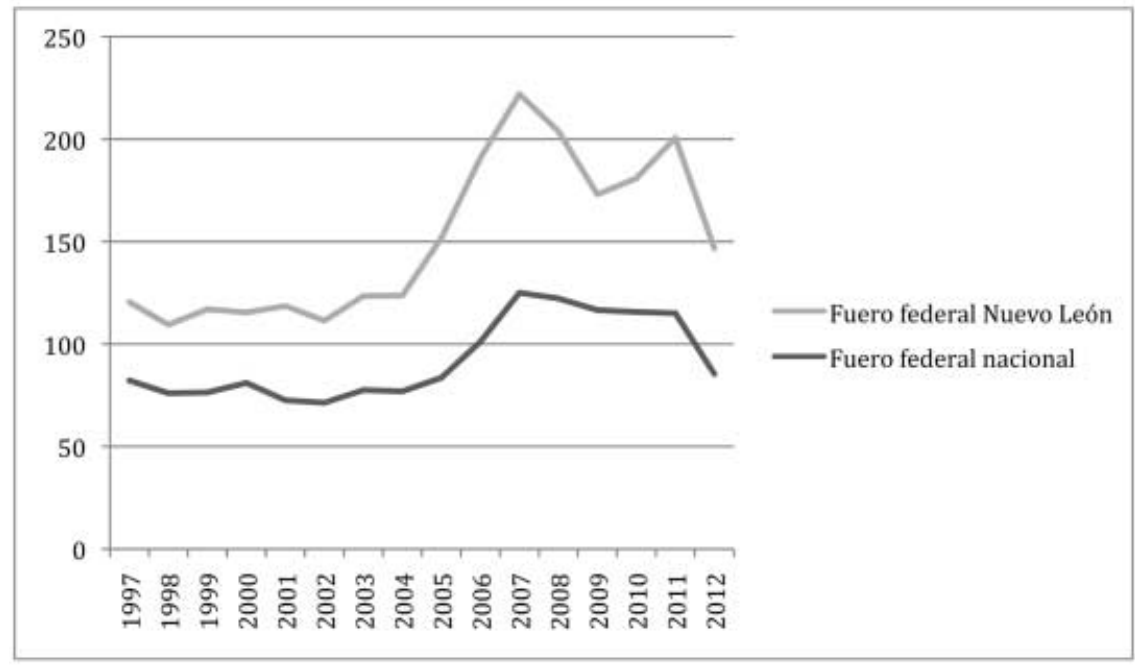

Figura 2 - Incidencia delictiva del fuero federal reportados a nivel nacional y en NL por cada 100 mil habitantes

Fuente: Sistema Nacional de Seguridad Pública 
comenzaron a reducirse, nunca regresaron a los niveles previos a la crisis, tal como se muestra en la figura y como indica la literatura desarrollada por Guerrero (2011).

Una de las transformaciones más importantes en esta crisis que vivió Nuevo León, fue el cambio en la selección de las víctimas. La evidencia deja en claro que los hechos violentos que antes sólo podían ocurrirle a los involucrados en disputas asociadas al crimen organizado, se hicieron tangibles para prácticamente toda la población. Es decir, han pasado de una operación donde la violencia sólo se restringía a objetivos bien establecidos a otro formato donde la violencia ha sido coyuntural, es decir, sin víctimas predefinidas. Para ejemplificar lo anterior, la Figura 3 presenta un diagrama que pretende explicar la evolución de la espiral de violencia en Nuevo León.

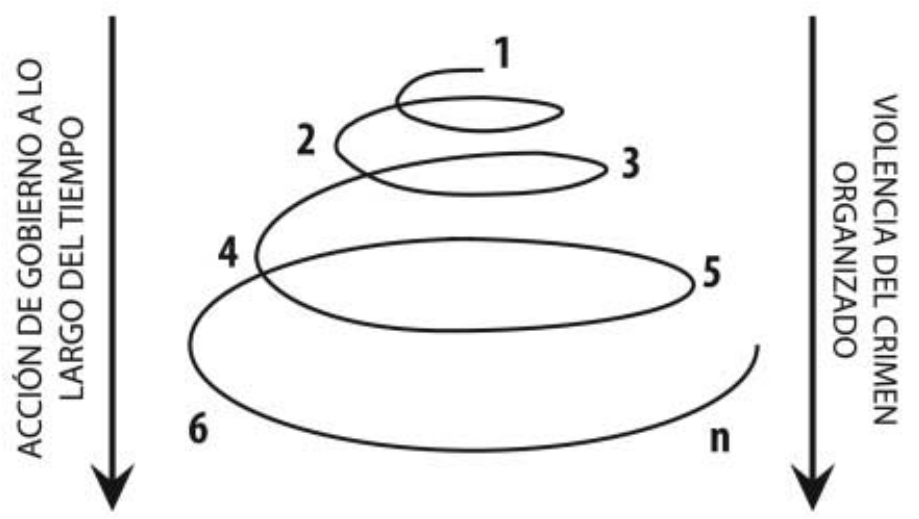

Figura 3 - Espiral de la violencia

Fuente: Elaborada por los autores

Según se desprende del gráfico anterior:

- En la fase uno (pre-crítica), el Estado tiene el monopolio de la fuerza legal, legítima y operativa. Como tal, lo ejerce cabalmente.

- En la fase dos (reto al Estado), el crimen se aprovecha de un incremento en capacidades para a) lavar dinero como producto de la globalización bancaria; b) importar ilegalmente armas de mayor poder después del cambio legal de EUA en 2004 (Pérez Esparza y Weigend, 2013); y c) contratar capital humano, quien ante la falta de oportunidades educativas y laborales, desigualdad y corrupción, ve esta opción como viable. El reto es racional porque el negocio es rentable.

- En la fase tres (respuesta estatal), el Estado reacciona al reto con: a) la adquisición de armas más violentas para reducir la brecha de 
poder de fuego con el crimen organizado (como lo hizo con Iniciativa Mérida) y b) el uso de las Fuerzas Armadas (a partir de 2007) para enfrentar a las células delictivas.

- En la fase cuatro (ventaja parcial del Estado), las autoridades parecen ser más fuertes que el crimen organizado, lo que le da legitimidad a la estrategia. Los ciudadanos, inclusive, ven con buenos ojos que el gobierno esté "inhabilitando" a los miembros de la delincuencia organizada. Se asume que los homicidios son de criminales, por lo que se consideran "indicadores de éxito" de la estrategia. El gobierno sigue pulverizando al crimen omitiendo que genera incentivos violentos a mediano plazo.

- En la fase cinco (escalada violenta) el crimen organizado responde con más violencia porque asume que el "premio" es potencialmente más probable que el "castigo". El crimen comprende que la mejor forma de debilitar al Estado es comenzando a ejercer la violencia aleatoria contra la población civil, algo que no había ocurrido antes. El Estado reacciona una vez más con la implementación de medidas más violentas e intrusivas (como los retenes en avenidas) para proteger la integridad de la sociedad. El crimen responde con brotes de narcoterrorismo (balaceras en eventos masivos; narcofosas; homicidios y secuestros a periodistas, empresarios famosos, alcaldes y figuras públicas; y detonación de granadas en espacios públicos). La estrategia del crimen organizado es reflejar su fuerza. La escalada de la violencia y del uso de armas de fuego se vuelve exponencial(n).

- En la fase seis (depresión colectiva), algunos ciudadanos comienzan a suponer que el Estado "va perdiendo la batalla" por su incapacidad para detener el daño ocasionado por el crimen y por los propios errores de los policías o militares. Ante una criminalidad menos adversa al riesgo y un Estado incapaz de contener los altos índices de incidencia delictiva, la ciudad se enfrentó al cierre de negocios, al cambio de hábitos y al éxodo de miles de sus habitantes (Durin, 2012). Con lo anterior, Nuevo León fue, de hecho, el estado mexicano que más cambió en menos tiempo (González-Aréchiga, Weigend, Pérez Esparza, \& Hernández, 2012).

¿Cómo explicar que la inseguridad y la violencia hayan aumentado considerablemente en tan poco tiempo en una ciudad en la que las oportunidades de empleo y de educación para todos sus habitantes eran tangibles? La respuesta es difícil pero simple: contrario a lo que muchos regiomontanos de las clases medias y altas quisieran suponer, la ZMM tenía-y tiene-importantes déficits estructurales en materia de desarrollo humano y urbano que permitieron que eso ocurriera. Como referencia, 
en mayo 2014, durante el Foro Internacional de Ciudades Globales y Movilidad Social, el Gobernador de Nuevo León, Rodrigo Medina, reconoció que en la ZMM prevalecían grandes déficits en materia de desarrollo urbano, tema que impactaba la calidad de vida de las personas (Mendieta, 2014). Por otro lado, el Consejo Nacional de Evaluación de la Política de Desarrollo Social (CONEVAL) reportó que en 2012 el 23.2\% de la población de Nuevo León vivía en condiciones de pobreza.

Pese a lo anterior, Monterrey ha conservado su imagen vanguardista en materia de competitividad y de acceso a oportunidades laborales y educativas (IDB, 2009). La explosión de la violencia en dicho contexto pareciera incluso paradójica, pues de hecho, los incentivos para el incremento del problema parecían no estar alineados ${ }^{11}$. Un posible determinante de la violencia es el tema geográfico, ya que Nuevo León -al igual que otros estados del norte- son territorios en disputa por parte del crimen organizado en su intención de controlar las rutas de acceso a Estados Unidos.

La crisis de inseguridad ha tenido consecuencias muy serias en la entidad. Personas e instituciones han cambiado sus horarios y estilos de vida, lo que ha generado el cierre de algunas actividades productivas y el retraso en el inicio de inversiones. Por ejemplo, en el periodo de 20082009, entre el 30 y 40\% de los comercios de la ZMM cerraron sus puertas porque sus propietarios fueron víctimas de extorsiones, en las que se les obligaba a pagar semanalmente entre el 20 y $30 \%$ del total de sus ventas (Excelsior, 2011). También existen reportes de la emigración de personas de la entidad, incluyendo estudiantes, empresarios y familiares de residentes (Severin, 2012).

La percepción de inseguridad en Nuevo León es un claro determinante de la evolución de este fenómeno a nivel local. Según datos del ICESI, en el 2002 sólo el 34\% de los neoloneses sentía que vivía en un estado inseguro. Dos años después, en el 2004, la cifra ya rondaba el $41 \%$. Cinco años más tarde, en el 2009, 70\% de los habitantes de Nuevo León se sentía inseguro. Como se observa en la Figura 4, para 2012 la cifra ya se había duplicado al $86.7 \%$.

Como consecuencia, Nuevo León comenzó a perder sus argumentos de estado líder en materia económica y de seguridad. Por el contrario, su riqueza acumulada pareció ser un imán para las organizaciones delictivas, colocándolo rápidamente como uno de los estados más violentos del país (Gonzalez-Aréchiga, Weigend, Pérez Esparza y Hernández, 2012). De poco sirvió el orgullo ciudadano o la relativa confianza que se tenía antes sobre las instituciones locales. Los hábitos de los regiomontanos habían cambiado dramáticamente en muy poco tiempo y sus líderes empresariales y políticos se vieron rebasados ante el tamaño del problema. El estado ocupó el tercer lugar en cambios de hábitos urbanos debido al problema 


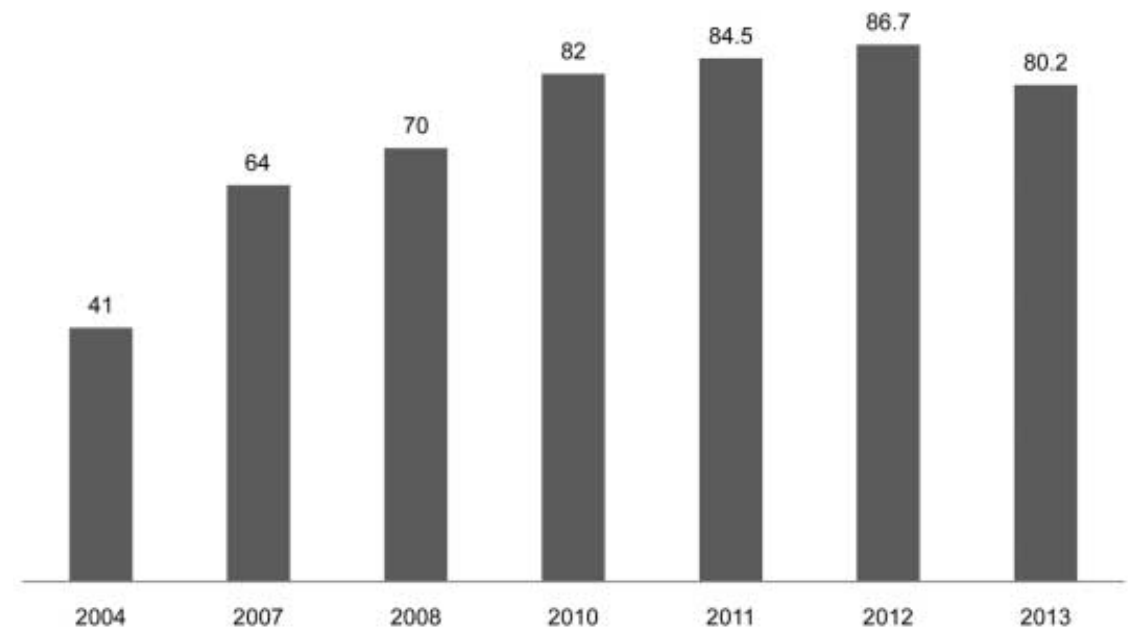

Figura 4 - Porcentaje de la población de Nuevo León que se percibía como insegura

Fuente: Encuesta Nacional sobre Inseguridad y Encuesta Nacional de Victimización y Percepción sobre Seguridad Pública

de inseguridad (Tercer Sector, 2011). Nuevo León fue víctima de un cambio radical, de un verdadero shock para el que no estaba preparado ${ }^{12}$. En la práctica, un fenómeno parecido a lo que experimenta una persona cuando pierde a un ser querido: el duelo.

\section{El duelo: La perspectiva clásica psicológica-individual}

El interés en el estudio del duelo es tan antiguo como la humanidad misma. Hoy se sabe que varias de las civilizaciones, como los mayas, los chinos, los indios, los aztecas y los egipcios, habrían querido explicar no sólo la muerte, sino lo que ocurre con las personas alrededor de la persona fallecida (Rosenblatt, Walsh y Wackson, 1976). Desde una perspectiva mucho más contemporánea, es la psicología con Sigmund Freud la que ciertamente formaliza el estudio de este fenómeno humano.

Aunque las definiciones son distintas, el duelo (que proviene del latín dolus, dolor) ha sido entendido como el proceso humano de reacciónprincipalmente emocional, psicológica, fisiológica y social-que conlleva el sufrimiento y la aflicción ante una pérdida significativa. Esta pérdida, puede ser de una persona, un animal o un objeto. Sin embargo, el duelo también puede ser la pérdida de algo más intangible; es decir, la melancolía vinculada a un evento, un momento, una relación, una circunstancia o a un cambio asociado a alguna de ellas (Freud, 1917; Bowlby, 1980; Cal- 
vet, 1996; Carpenito, 1987; DSM-IV, 1995; Lafuente, 1996; Valdés \& Blanco, 1997).

Por lo general, la manifestación externa del duelo se llama luto. Este conlleva a la aparición de reacciones que se exteriorizan de formas distintas, a veces de manera simultánea o unas antes que otras (Fernández \& Rodríguez, 2002).

Más allá de las manifestaciones y expresiones, los psicólogos y los analistas clínicos que estudian al duelo han coincidido que más que un estado permanente, éste es un proceso dinámico compuesto de varias fases. A éstas les llaman "elaboración del duelo"; es decir, el recorrido de impactos que va desde la pérdida hasta la asimilación de la misma. Sin embargo, a pesar de esta coincidencia, los analistas de este proceso disienten en el número de las fases que componen al duelo (o más generalmente, una situación inesperada de cambio). Prueba de ello es la literatura producida desde hace más de sesenta años, en la cual es evidente que no hay consenso sobre las fases que componen el duelo, pese a que existe una evidente generalización en sus determinantes (ver Bourgeois \& Verdoux, 1994; Fernández \& Rodríguez, 2002; Filgueira, 1995; Grollman, 1986; Lewin, 1947; Neimeyer, 2002; Parkes, 1975; Rando, 1988; Valdés \& Blanco, 1997).

Aunque las etapas no son universales, es decir, no se espera que necesariamente todos los individuos sujetos a este shock deban atravesar por ellas en una determinada secuencia, generalmente se prevén varios puntos en común. Después de la pérdida se presenta un primer momento de aturdimiento, negación, o gran impacto emocional, en el que el individuo hace lo posible por no aceptar la realidad. Después de éste, hay una

Tabla 1 - Manifestaciones y expresiones corrientes del duelo

\begin{tabular}{ll}
\hline Manifestación & Expresiones \\
\hline Sentimientos & Tristeza, rabia, irritabilidad, culpa, reproches, indefensión. \\
\hline $\begin{array}{l}\text { Sensaciones } \\
\text { físicas }\end{array}$ & $\begin{array}{l}\text { Molestias en el cuerpo, hipersensibilidad, falta de apetito, debi- } \\
\text { lidad, pérdida de energía, trastorno del sueño, estrés anormal. }\end{array}$ \\
\hline Cogniciones & $\begin{array}{l}\text { Confusión, dificultades de memoria, preocupación, pensa- } \\
\text { mientos obsesivoides e intrusivos. }\end{array}$ \\
\hline $\begin{array}{l}\text { Alteraciones } \\
\text { perceptivas }\end{array}$ & $\begin{array}{l}\text { Ilusiones, alucinaciones auditivas y visuales. } \\
\text { Conductas }\end{array}$ \\
$\begin{array}{l}\text { Alteraciones del sueño, distracciones, abandono de relacio- } \\
\text { nes sociales, evitación de lugares y situaciones, inquietud, } \\
\text { hiperalerta, llanto, remembranza de símbolos vinculados a la } \\
\text { pérdida. }\end{array}$ \\
\hline
\end{tabular}

Fuente: Fernández y Rodríguez, 2002 
macro fase de estados intermedios (compuesta por una, dos o hasta tres sub-fases) en donde se presenta la desorganización de emociones, sobre todo de desesperanza, depresión y sentimientos de cólera contra aquellos a quienes se considera responsables de la pérdida (una tercera persona o inclusive, el individuo mismo). Por último, hay una etapa final en la cual aparece la reorganización y la aceptación de la pérdida (Ortego \& Alconero, 2001).

De todos estos enfoques de la psicología, psiquiatría y aun de otras disciplinas, destacamos la reconocida aportación de la psiquiatra Elisabeth Kübler-Ross quien, después de estudiar empíricamente el comportamiento de personas moribundas, por primera vez sentó las bases del estudio clínico del duelo. Como resultado de su obra original (1969) y de otros doce trabajos posteriores, presentó un modelo de cinco etapas en las cuales se desarrolla el duelo: negación, ira, negociación, depresión y aceptación.

\section{El duelo: la perspectiva sociológica-colectiva}

Podemos identificar cambios traumáticos no deseados (inesperados) experimentados por grandes grupos de población en casos como los desastres aéreos internacionales, los contextos bélicos de Medio Oriente, migración y exilio forzados, incluso en situaciones como el fin del comunismo en Hungría. Situaciones de cambio que están asociadas en cierta medida a la melancolía y a las emociones colectivas vinculadas al duelo. Una revisión de la literatura permite presentar algunos ejemplos de ello.

Está claro que los argumentos elaborados por la psicología y la psiquiatría son útiles para comprender el duelo en lo individual. Sin embargo, la tabla anterior refleja algunos precedentes que han explicado la

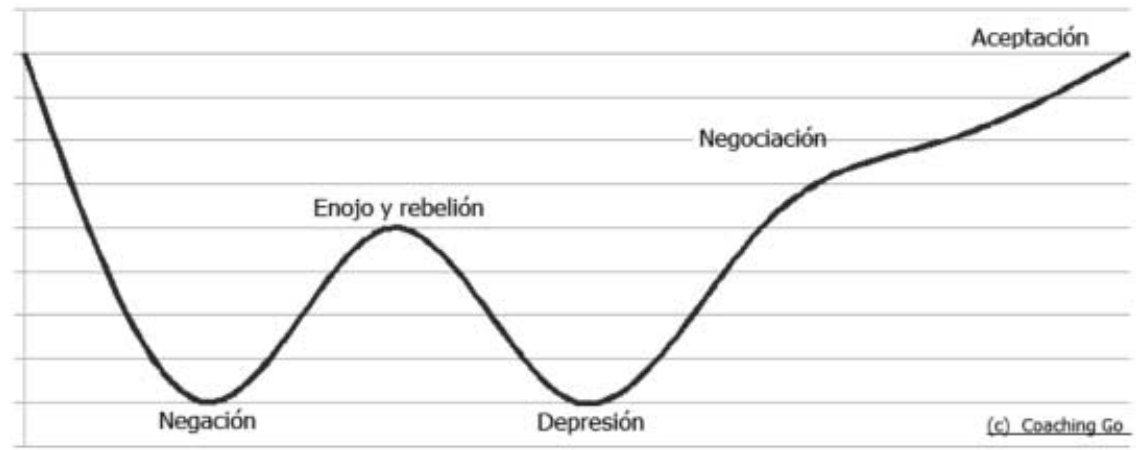

Figura 5 - Modelo Kübler-Ross

Fuente: Elaborado por los autores a partir de Kübler-Ross 
Tabla 2 - Ejemplos de interpretaciones colectivas del duelo

\begin{tabular}{|c|c|c|}
\hline Ejemplo & Duelo debido a: & Autor: \\
\hline $\begin{array}{l}\text { Incertidumbre } \\
\text { post comunista } \\
\text { en Hungría }\end{array}$ & $\begin{array}{l}\text { 1. Inseguridad colectiva sobre el futuro: roles, } \\
\text { reglas, normas, funciones e intereses } \\
\text { 2. Cambio drástico en variables idiosincráticas } \\
\text { 3. Añoranza por la certidumbre y la estructura }\end{array}$ & $\begin{array}{l}\text { Bunce y } \\
\text { Csanádi, } \\
1993\end{array}$ \\
\hline Migrantes & $\begin{array}{l}\text { 1. Separación de familia y amigos } \\
\text { 2. Abandono de lengua materna } \\
\text { 3. Melancolía por la cultura } \\
\text { 4. Añoranza por los paisajes y la tierra } \\
\text { 5. Pérdida de estatus social } \\
\text { 6. Pérdida de contacto con la etnia nacional }\end{array}$ & $\begin{array}{l}\text { Atxotegui, } \\
2000\end{array}$ \\
\hline $\begin{array}{l}\text { Exiliados } \\
\text { cubanos } \\
\text { en EUA }\end{array}$ & $\begin{array}{l}\text { 1. Separación de familia y amigos } \\
\text { 2. Abandono de lengua y cultura materna } \\
\text { 3. Melancolía por la propiedad privada en Cuba } \\
\text { 4. Sentimiento de minoría }\end{array}$ & $\begin{array}{l}\text { Lorenzo, } \\
2005\end{array}$ \\
\hline $\begin{array}{l}\text { Nostalgia } \\
\text { comunista en } \\
\text { Varsovia y } \\
\text { Berlín }\end{array}$ & $\begin{array}{l}\text { 1. Despolitización } \\
\text { 2. Ausencia de íconos urbanos }\end{array}$ & $\begin{array}{l}\text { Bartmanski, } \\
2011\end{array}$ \\
\hline
\end{tabular}

Fuente: Elaborado por los autores a partir de revisión de literatura

pérdida "de algo" y su impacto en el duelo colectivo. Este documento retoma esa lógica y sugiere que el mismo racional permitiría comprender cómo una sociedad que se consideraba a sí misma como la más segura respondió colectivamente a una de las mayores crisis de su historia.

Nuevo León, y de manera particular Monterrey, experimentó las cinco etapas del duelo durante la reciente ola de inseguridad y violencia. A continuación se presenta una explicación de cada una de esas etapas a través de una breve descripción del imaginario colectivo en el ámbito político, empresarial-económico y social-educativo. Para realizar un contraste, se incluye una etapa cero, en donde se retoma la percepción que existía antes de la crisis de inseguridad.

\section{Etapa cero. Pre traumática: Nuevo León, estado líder en México y Latinoamérica}

En el ámbito político, Nuevo León se percibía como uno de los estados mexicanos más democráticos, al ser uno de los primeros en experimentar la transición en Alcaldías, Congreso y la Gubernatura de un partido distinto al Partido Revolucionario Institucional en 1997 (Medellín, 2006). A su vez, se consideraba que la policía estatal de Nuevo León, las policías 


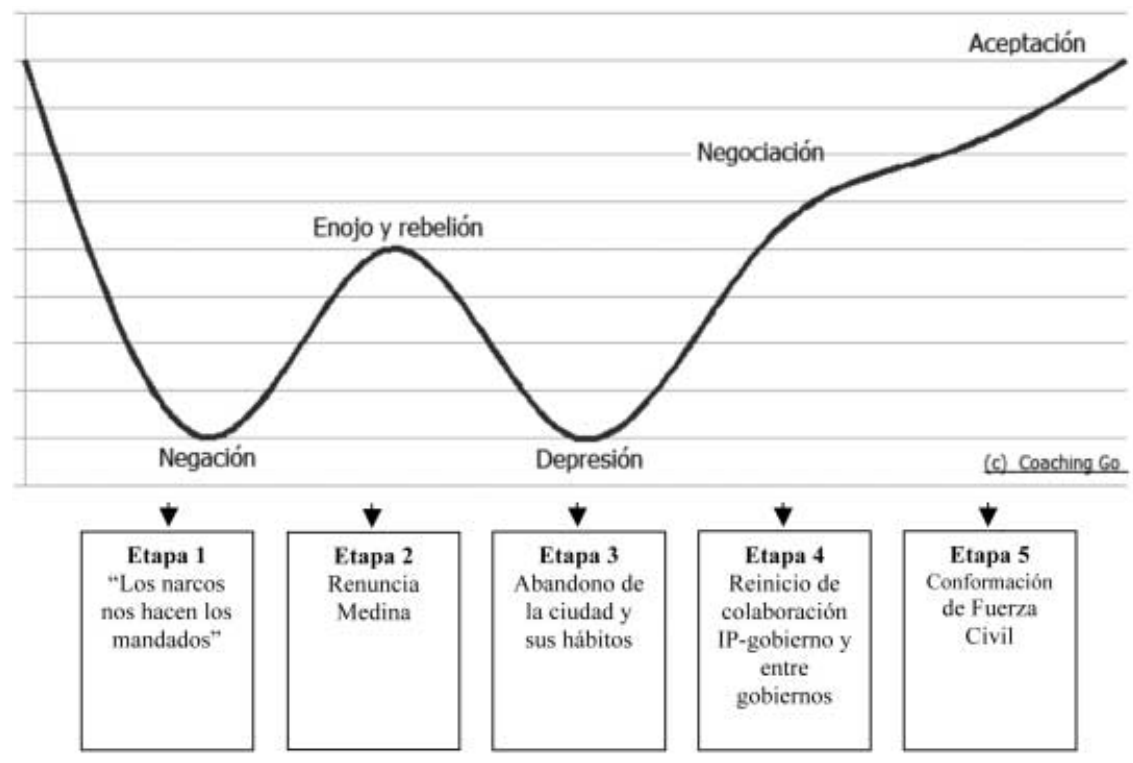

Figura 6 - Las etapas del duelo y la crisis de seguridad en Nuevo León Fuente: Elaborada por los autores

municipales y, en general, el aparato de justicia gozaban de mejores indicadores de confianza que el resto del país (ICESI, 2012).

En el área económica, Nuevo León se sabía heredero de un empresariado que fue líder a nivel nacional durante el siglo 20 y que con el Tratado de Libre Comercio con Canadá y Estados Unidos sería la punta de lanza en el siglo 21. Existía la presunción de ser el único polo de poder que podía desafiar al poder nacional de la Ciudad de México.

Su sociedad se caracterizaba por sentir un particular orgullo por vivir en una ciudad/entidad con los niveles de riqueza y desarrollo humano más altos del país; lo anterior alimentaba un sentimiento de superioridad con respecto al resto de los mexicanos. Un ejemplo de ello era la idea generalizada de que con los impuestos que Nuevo León aporta a la federación se mantenía a otras entidades. Otro, que Nuevo León fuera conocido por contar con universidades líderes, como el Tecnológico de Monterrey, la Universidad Autónoma de Nuevo León, la Universidad de Monterrey, entre otras, las cuales atraían a estudiantes de todo México y del mundo.

\section{Etapa uno. Negación: Nuevo León negó sus problemas de inseguridad}

En el año 2000, el ex-gobernador Fernando Canales hizo mención de algunas frases que trataban de minimizar o simplemente negar que existieran problemas de inseguridad. Un botón de muestra fue: “En Nuevo León no 
hay homicidios vinculados al narco. El narco opera en Tamaulipas ${ }^{13}$ y sólo deja los cuerpos en Nuevo León" (2000). Por si fuera poco, "El narco nos hace los mandados" (2001).

Años más tarde, incurriendo en deuda pública, el gobierno del estado organizó el Foro Universal de las Culturas de 2007 y con grandes proyectos de infraestructura (como la extensión del metro y del Parque Fundidora), simuló que no había problemas de inseguridad.

Así como la esfera política no reconocía el problema de inseguridad, las cámaras empresariales tampoco pusieron el tema sobre la mesa. En ese momento, los empresarios no participaban en temas relacionados con violencia e incidencia delictiva. Por su parte, la sociedad sabía que existían brotes de violencia, pero los veía lejanos a su realidad, situación que puede ser explicada con las cifras de percepción de inseguridad de la Figura 4. Las poblaciones universitarias se mantienen alejadas del problema, no participan en el debate público, ni toman medidas especiales en contra del crimen.

\section{Etapa dos. Ira: Nuevo León se culpó mutuamente}

Ante un crecimiento en incidencia delictiva que ya imposibilitaba ocultar más el problema, los políticos comenzaron a culparse mutuamente (Tapia, 2009). Los esquemas de coordinación entre diferentes niveles de gobierno y de diferentes partidos, casi nulos, prácticamente desaparecieron. Lo anterior se volvió más crítico ante las revelaciones de los cables diplomáticos de Wikileaks (consultas previas a la elaboración de este artículo en 2014), mismos que revelaron la incompetencia de algunos servidores públicos y los presuntos vínculos con el crimen organizado de otros (SIPSE, 2011).

La economía se vio seriamente afectada a causa de balaceras en espacios públicos, secuestros de empresarios, asaltos en carreteras, lanzamiento de granadas en plazas públicas, ejecuciones de grupos rivales en puentes, entre otras nuevas manifestaciones de violencia. A consecuencia de esto, durante 2010 se cerraron unas 300 empresas y 300 más se mudaron a Texas, en Estados Unidos (García, Fernández, \& Portales, 2011). Los empresarios culparon a las autoridades del crecimiento en incidencia delictiva utilizando a las Cámaras tradicionales. ${ }^{14}$

Se presentó el fenómeno de "los tapados", en el que "delincuentes" de colonias marginadas secuestraron automóviles y camiones urbanos para desquiciar el tráfico por horas, pidiendo la salida del Ejército de Nuevo León. La autoridad fue incapaz de detener estas manifestaciones, mismas que ocurrieron por varios días. Trasciende que estos grupos eran financiados con recursos del crimen organizado. Las universidades arremeten contra las autoridades por la pérdida histórica de estudiantes. Inició el 
movimiento "Renuncia Medina" en el que, por primera vez en la historia, ciudadanos se reunieron una vez por semana en la Macroplaza (plaza principal del estado) para exigir la salida del gobernador Rodrigo Medina. Lo acusaron de incompetente.

\section{Etapa tres. Negociación: Nuevo León buscó una primera salida a la crisis}

Como claro símbolo de desconfianza, los líderes empresariales presionaron a la administración estatal entrante en 2009 para que incorporara a figuras de las Cámaras y empresas en el equipo de transición y en el gobierno, bajo la premisa de que el sector privado podría controlar mejor la situación. Así llegaron Vidal Garza, funcionario de Fomento Económico Mexicano (FEMSA), al equipo de transición gubernamental; Javier Treviño, funcionario de Cementos Mexicanos (CEMEX) a la Secretaría General de Gobierno; Othón Ruiz Montemayor, funcionario del Banco Mercantil del Norte (Banorte) a la Tesorería del estado; Fernando Gutiérrez Moreno, funcionario de la Cámara de la Industria de Transformación (CAINTRA) a la Secretaría de Desarrollo Sustentable; y Jorge Tello Peón, funcionario de Cementos de México (CEMEX) como Asesor del Gobernador en materia de seguridad e interlocutor con el gabinete federal de seguridad. Algunas organizaciones civiles y universidades comenzaron a participar en proyectos con gobiernos. Sin embargo, eran la minoría.

\section{Etapa cuatro. Depresión: Nuevo León sufrió cambios en sus hábitos}

La clase política fue testigo de cómo funcionarios públicos (policías y agentes de tránsito) eran secuestrados y asesinados por el crimen organizado. Ocurrió el múltiple ataque al Alcalde de la ciudad de García, el secuestro del Secretario de Tránsito de Monterrey y el homicidio del Alcalde de la ciudad de Santiago. Además, se presentó el ataque al Consulado de Estados Unidos. La percepción generalizada era que "todos eran vulnerables".

En la percepción, se consideraba muy riesgoso utilizar las carreteras y se conocieron más casos de empresarios secuestrados y extorsionados. Algunas empresas cerraron y en otros casos, los dueños de empresas insignia de la ciudad emigraron a Texas o a otras ciudades en el extranjero ${ }^{15}$, haciendo evidente la frustración por parte del empresariado ${ }^{16}$.

Con un crimen que ahora además quería controlar la información, se presentaron casos de persecución a periodistas por parte del crimen organizado, así como ataques a la infraestructura de los medios de comunicación que reportaron las operaciones del crimen. Por primera vez, Consulados de varios países señalaron a Monterrey como una de las ciudades más peligrosas de México y, en consecuencia, sugirieron evitar visi- 
tarla (La Razón, 2010). Por las balaceras, extorsiones y secuestros, muchos regiomontanos dejaron de visitar zonas sensibles de la ciudad (ejemplo: Barrio Antiguo). La vida nocturna y en espacios públicos prácticamente desapareció (Canales, 2011). Este evidente cambio de hábitos en la sociedad urbana afectó incluso a las universidades, las cuales comenzaron a perder cada vez más estudiantes (Torres, 2011). Hubo una percepción generalizada de corte "depresiva" por "estar perdiendo la ciudad".

\section{Etapa cinco. Aceptación: Nuevo León comenzó a trabajar en conjunto}

En 2011, surgieron las primeras reuniones de coordinación entre los Alcaldes, el gabinete estatal, el Ejército y la Marina. La alcaldía de la ciudad de Escobedo comenzó a trabajar con vecinos y empresas en el esquema de Policía de Proximidad ${ }^{17}$. Por su parte, la Alcaldía de Monterrey incluyó a miembros de la Marina para supervisar áreas en las que había evidencia de corrupción (alcoholes, tránsito, policía). Mientras, la Alcaldía de la ciudad de San Pedro aceptó la colaboración del Ejército en su Centro de Comunicaciones, Cómputo, Control y Comando (C4). Aunque las tensiones continuaban, existía comunicación.

La Iniciativa Privada modificó el tono de sus críticas a esquemas más propositivos. Así nacieron programas como "Alcalde, ¿cómo vamos?"18 de CCINLAC; el Consejo Estatal para la Promoción de Valores y Cultura de la Legalidad con el apoyo de empresarios; "Hagámoslo bien" de COPARMEX, proyecto que promueve la Cultura de la Legalidad; y Evolución Mexicana y Vertebra, junto con otras organizaciones y colectivos, promovieron la Ley de Participación Ciudadana. Por primera vez en la historia se aceptó que gran parte de la crisis se debía a la ausencia de una policía capaz en Nuevo León. A raíz de lo anterior, los líderes de universidades y de una decena de empresas participaron directamente en la conformación de Fuerza Civil, proyecto que pretende renovar a la Policía de Nuevo León. Las sesiones de trabajo se llevaron a cabo en la Escuela de posgrado de Política Pública -EGAP del Tec de Monterrey- y aunque existieron tensiones entre funcionarios indispuestos a trabajar en equipo con gente de la Iniciativa Privada, el proceso avanzó (Vanguardia, 2011).

De manera paralela, por primera vez las universidades participaron en la implementación de varios proyectos del Subsidio para la Seguridad Municipal (SUBSEMUN) sobre todo en materia de prevención del delito. Por ejemplo, además de participar en la conformación de Fuerza Civil, la propia EGAP participó en proyectos de reforma al aparato de justicia; políticas contra la discriminación, opciones para la regulación de drogas; reordenamiento urbano para reducir la criminalidad (Revive Monterrey); estudios sobre incidencia delictiva y un proyecto de reforma policial, entre otros. 
Después del proceso de inseguridad que se vivió en el estado, se hicieron evidentes una importante cantidad de puntos vulnerables, de diferentes índoles. Como lo hemos mencionado, uno de ellos fue la limitada cantidad de cuerpos policiacos. Pero entre los puntos vulnerables más destacados estuvieron las restricciones legales y operativas. Las primeras vinculadas a la aparentemente ineficiente descentralización de los servicios de seguridad. Constitucionalmente (artículos 21 y 115 de la Constitución Política mexicana), los municipios, el estado y la federación tienen responsabilidades en la provisión de los servicios de seguridad. En la práctica, esta función recae principalmente en el estado, mientras que la federación atiende los delitos federales, y los municipios la función preventiva.

Las restricciones operativas comprendieron el limitado número de policías más el limitado número de operaciones de seguridad urbana. Nuevo León tenía sólo 6,000 elementos sumando policías estatales y municipales. De éstos, 4,000 cuidaban los bancos o fungían como escoltas de funcionarios, pero no en labores policiales, lo que implicaba un déficit de al menos 8,000 según los estándares de Naciones Unidas (Revista Sin embargo, 2011). Por si fuera poco, era evidente la infiltración por parte del crimen organizado, demostrado por decenas de arrestos que el Ejército llevó a cabo a elementos en activo. La reconstrucción institucional se aceptó como un primer paso.

La fase de aceptación comenzó a llegar a Nuevo León entre 2009 y 2010 con algo que, en principio, no tenía nada que ver con lo que finalmente ocurrió. En ese entonces, el Presidente Felipe Calderón había propuesto que las entidades conformaran un "Mando Único Estatal", fusionando las corporaciones municipales. Los partidos de oposición no fueron claros. Algunos líderes políticos apoyaron la iniciativa, otros la criticaron. La mayoría, ya en campaña presidencial, simplemente ignoró la propuesta.

Cuando el Presidente se dio cuenta de que la reforma no sería aprobada, el gabinete de seguridad presentó una alternativa de política pública. Se diseñó un subsidio llamado "Policía Acreditable" o SPA (Secretariado Ejecutivo del SNSP, 2012), destinado a fomentar la profesionalización de los policías estatales. Aquellos estados que pasaran varias pruebas y demostraran que sus policías eran confiables, recibirían 100 millones de pesos de incentivo el primer año (con posibilidad de incrementarlo a futuro). Eventualmente, se esperaba que las policías estatales mejorarían considerablemente, tanto que en muy poco tiempo los propios Alcaldes cederían voluntariamente, primero el mando y después, las corporaciones mismas.

Este proyecto tuvo una buena acogida en Nuevo León como no tuvo en ninguna otra parte del país por el simple hecho de que el Gobernador tenía escasos meses en funciones y a pesar de ello, era víctima de duras 
críticas tanto del empresariado como de la sociedad; ambos exigiendo su renuncia. El subsidio parecía una alternativa. El gobierno estatal intentó reclutar policías por sí mismo, pero debido al riesgo, al bajo salario y al pésimo concepto asociado a dicha profesión, simplemente fue incapaz de lograrlo.

Finalmente, surgió la idea de que fuera la propia Iniciativa Privada regiomontana la que colaborara con esta tarea. Sin embargo, no había interlocutor en el gobierno estatal que fuera capaz de convencer a los empresarios. Para ello, en un acuerdo entre el Presidente Calderón y el gobernador Medina, se planeó que fuera Jorge Tello Peón, hombre con una larga trayectoria en seguridad federal y muy cercano a la Iniciativa Privada, quien hiciera las primeras gestiones "en nombre del Presidente". En enero de 2010, Tello Peón dejó la Secretaría Ejecutiva del Sistema Nacional de Seguridad Pública en la Ciudad de México y se trasladó a Monterrey para llevar a cabo su encomienda.

A partir de entonces, la tarea fue convencer a empresarios sobre la necesidad de colaborar en una campaña inusual de reclutamiento policial, no sólo en Nuevo León, sino en todo México. La propuesta era innovadora: las empresas cederían el tiempo de dos o tres altos ejecutivos en las áreas de mercadotecnia, logística, ventas y recursos humanos para planear y ejecutar desde cero esta campaña. Naturalmente, a las reuniones acudirían aproximadamente diez funcionarios estatales, de la Procuraduría, de la Secretaría de Seguridad Pública estatal y de la Secretaría General de Gobierno.

El acuerdo señalaba que las tareas de planeación se realizarían en dos o tres horas al día en las instalaciones de la EGAP, en San Pedro, Nuevo León. Habría un equipo de ocho consultores privados que fungirían como el soporte a todo el equipo. Además de la EGAP del Tecnológico de Monterrey, otras cinco universidades participarían con el tiempo de investigadores y personal administrativo en el proyecto: el Centro de Estudios Universitarios (CEU), la Universidad de Monterrey (UDEM), la Universidad Autónoma de Nuevo León (UANL), la Universidad Metropolitana de Monterrey y la Universidad Regiomontana (UR). Se crearía un concepto de policía renovada y confiable, con salarios altos y mayores prestaciones, pasarían pruebas múltiples de confianza, y serían entrenados con apoyo militar en una nueva academia policial.

En algún punto, la Iniciativa Privada, que primero se mostró reacia a participar, terminó aceptando la invitación. Así, finalmente se convenció a que empresas tan distintas como Alfa ${ }^{19}, \mathrm{CEMEX}^{20}$, Soriana ${ }^{21}$, Axtel ${ }^{22}$, Xignux $^{23}$, FEMSA ${ }^{24}$ y Alliax ${ }^{25}$ se unieran a las Universidades y participaran activamente en el proyecto. Las reuniones de planeación duraron meses. La tarea no fue fácil. Los funcionarios no estaban acostumbrados a tra- 
bajar con personas de la Iniciativa Privada, ni éstos con burócratas. En muchas ocasiones el conflicto se presentó porque los representantes de las empresas dudaron de las promesas de los funcionarios del gobierno (y viceversa).

En cualquier caso, el modelo pareció haber funcionado. A varios meses de esta iniciativa mixta, el impulso que la Iniciativa Privada infligió al gobierno del estado de Nuevo León ofreció resultados que no se pueden ignorar. Se creó una nueva imagen para una organización que antes representaba lo peor del estado, se ejecutó una campaña nacional de reclutamiento, se cambiaron las patrullas y poco a poco más jóvenes consideraron la posibilidad de unirse a esta corporación. Naturalmente, lo más importante, es que se reclutó a policías de todo el país que han logrado pasar las cinco pruebas de confianza ${ }^{26}$ (la médica, la toxicológica, la de aptitudes físicas, la psicológica y la de entorno social-patrimonial). Por ello, a pesar todo, Fuerza Civil ha logrado niveles de posicionamiento que aunque aún son bajos, parecen prometedores, considerando lo complicado de su origen ${ }^{27}$.

Fuerza Civil está aún lejos de ser una corporación perfecta. Varios de sus elementos han sido detenidos por corrupción o por participar directamente en delitos. Aun así, la transformación se mantiene para crear lazos que la acerquen al ciudadano y todo parece indicar que la Iniciativa Privada sigue ejerciendo presión para que la corporación se mantenga y mejore su imagen. A partir de 2014, por ejemplo, Fuerza Civil habrá de implementar un esquema de patrullaje más cercano a la gente en la zona sur de Monterrey. Cuatro elementos se han considerado: un modelo de proximidad; un cambio de uniformes a colores claros (no con los distintivos tonos militares con los que nació); un cambio del arma larga por una corta; y el uso de los nuevos autos Ford Interceptor para patrullaje en lugar de las camionetas amenazantes y de gran tamaño que se usaron en un inicio. La evolución de Fuerza Civil parece que simboliza el quinto proceso de duelo que vivió Monterrey, un proyecto en el que participaron activamente gobierno, empresa y sociedad civil. Aún incipiente, pero de aceptación activa del reto que tiene enfrente.

El caso de Fuerza Civil sirve como ejemplo de colaboración entre los diferentes sectores de la sociedad para resolver un problema muy concreto, el de las policías. Sin embargo, como se señaló anteriormente, los problemas de inseguridad y violencia necesitan ser abordados desde diferentes perspectivas. No se pueden dejar de lado los esfuerzos encaminados a fortalecer la cohesión social, tal como han sido implementados en ciudades como Medellín, Colombia y Rio de Janeiro, Brasil.

Medellín, la cual en décadas anteriores se caracterizó por altos índices de violencia, hoy mantiene una fuerte apuesta por la inversión en infraes- 
tructura, proyectos sociales de capacitación laboral y de oportunidades educativas para los jóvenes, políticas de participación ciudadana en la toma de decisiones, un fuerte liderazgo político, un proceso constante de rendición de cuentas y el restablecimiento en el control gubernamental en zonas anteriormente controladas por la delincuencia (Banco Interamericano de Desarrollo, 2007).

Monterrey, incluso, ha tomado bastante en serio las lecciones que Medellín tiene que ofrecer. En 2012, como parte de una iniciativa del Tecnológico de Monterrey, un grupo de 55 visitantes de Nuevo León, entre ellos 16 alcaldes electos y 1 alcalde en funciones visitaron dicha ciudad para conocer el proceso de transformación que ha vivido en los últimos años, a través de la educación, el urbanismo social y la apropiación de los espacios públicos (ITESM, 2012). Los líderes y la población de Nuevo León, sin duda, están trabajando en diversos frentes para combatir los problemas de inseguridad y violencia, el de la cohesión y prevención del delito no son la excepción. Lo interesante es que, al igual que en el caso de Fuerza Civil, son proyectos colaborativos entre gobierno, empresa y sociedad civil.

\section{Conclusiones}

Los fenómenos que se presentaron a partir de 2007 en Monterrey fueron traumáticos, inesperados y sin duda, dolorosos. Los empresarios sufrieron amenazas en sus negocios, e incluso en su persona; muchos de ellos abandonaron la ciudad. El gobierno, a la par de que pretendía reaccionar a la ola de violencia, se convirtió también en una víctima de ella misma y de lo que dejó de hacer por décadas. La sociedad en su conjunto vio afectado su estilo de vida, pero sobre todo, se convirtió en un rehén del crimen organizado: un duro golpe para su autopercepción de liderazgo y orgullo local. Un shock como nunca antes en su historia. Con sus variantes, cada uno de los ámbitos y actores de Monterrey atravesaron por una pérdida, por un duelo colectivo.

Ciertamente surgen muchos interrogantes de la experiencia que vivió Monterrey. ¿Fue la fortaleza económica e institucional, tan apreciada por muchos regiomontanos, insuficiente para hacer frente al problema? ¿Era dicha fortaleza producto de esfuerzos tangibles, o simplemente la ilusión de un conjunto de ideales propios de una identidad forjada hace décadas? ¿O se trató, más bien, de un problema de corresponsabilidad no asumida entre el gobierno, los empresarios y la ciudadanía? No parece haber una respuesta contundente. El proceso constructivo para entender qué salió mal, cuáles son las lecciones y cuáles son las mejores alternativas para superar el problema, aún no ha terminado. 
Aun así, hay muchas ideas que pueden servir al debate académico sobre la seguridad urbana y principalmente sobre las ciudades que pretenden reinventarse. Como se mencionó anteriormente, el caso de Medellín demuestra que líderes sociales, políticos y empresariales pueden reaccionar y trabajar en conjunto ante el descontento social ocasionado por los altos indicios de violencia. De la decepción y el miedo cotidianos, Medellín-entre otras urbes-desarrolló y compartió una sociedad civil asertiva y emprendedora, un liderazgo inclusivo y un empresariado con responsabilidad social para enfrentar el problema de seguridad. Puig (2009) señala que cualquier ciudad, esté como esté, puede optar por su rediseño.

Las cinco etapas de duelo que atravesó Monterrey, sin duda, hacen eco de lo descrito por Puig. Afortunadamente, las acciones tomadas recientemente por autoridades y ciudadanos, tal como ocurrió con Fuerza Civil, están arrojando avances significativos que hacen suponer que el duelo se está superando. La clase empresarial, con frases como: “No vamos a dejar que Monterrey se pierda", ha dejado en claro que tiene una responsabilidad y un compromiso con la ciudad y con el estado. El activo papel de la sociedad civil-estudiando, exigiendo y proponiendo-ha sido clave en la recuperación de la ciudad. El proceso no ha sido fácil ni inmediato, pero representa un claro ejemplo de participación público-privada en la construcción del bien público de la seguridad urbana. Dice Puig (2009) que el rediseño de una ciudad es una cuestión de voluntad, y parece que Monterrey -a su ritmo- fue capaz de comenzar de nuevo a forjarla.

En cualquier caso, a la par de políticas públicas para contener el problema de inseguridad y violencia, se necesita de una seria reflexión sobre las fortalezas y las debilidades del gobierno, las empresas y la sociedad civil. Queda pendiente una agenda para trabajar en los elementos necesarios para hacer más resilientes al estado de Nuevo León y a sus ciudades. Con lo anterior, se evitaría que las próximas grandes transformaciones sean resultado de otro duelo, -pues aunque en Monterrey lo hicieron-, ninguna ciudad debería estar condenada a evolucionar incentivada por el dolor.

\section{NOTES}

1. Correspondiente tradicionalmente a los municipios de Apodaca, García, San Pedro Garza García, Escobedo, Guadalupe, Juárez, Monterrey, San Nicolás y Santa Catarina.

2. El sujeto de análisis es el municipio de Monterrey; sin embargo, dependiendo del contexto, los autores pueden centrar el análisis en la ZMM o en el estado de Nuevo León. 
3. En 2011, 92\% de los regiomontanos declaró que cambió al menos uno de sus hábitos urbanos a consecuencia de la inseguridad que se vive en el área metropolitana (Animal Político, 2011).

4. De 1950 a 1980, la industria regiomontana creció $8.3 \%$ anual en promedio (Flores, 2011).

5. La palabra Monterrey se descompone en Monte y Rey, un monte regio o regio monte. "Regiomontano" es el gentilicio de Monterrey y "Regio" es su abreviación (Espinosa, 2009). De forma similar, "regio" es un adjetivo que significa grande, magnífico, o excepcional.

6. Entre las ciudades no-capitales en el mundo que identificamos experimentan una identidad similar se encuentran: Nueva York (EEUU); Kioto (Japón); Barcelona (España); San Petersburgo (Rusia); Milán (Italia); Río de Janeiro (Brasil); Quebec y Vancouver (Canadá).

7. En el año 2004, cuando se presentaron las primeras manifestaciones de inseguridad, sólo el 41\% de la población decía sentirse insegura; para 2012, la cifra ya se había duplicado al $86.7 \%$ (ICESI, 2009).

8. En el año 2001 el ex gobernador Fernando Canales hizo referencia a la superioridad del estado de Nuevo León versus el Crimen Organizado con la frase "El narco nos hace los mandados".

9. Los delitos del fuero común se refieren a aquellos que afectan directamente a las personas, entre estos se encuentran amenazas, daños en propiedad ajena, delitos sexuales, homicidios, robos, lesiones, entre otros. La competencia de estos delitos es de los estados, son perseguidos por los Ministerios Públicos del fuero común, investigados por las Procuradurías de Justicia y juzgados por el Poder Judicial de cada una de las entidades federativas.

10. Los delitos del fuero federal son aquellos que afectan de manera general al país, en las áreas de seguridad, salud y economía; entre estos delitos se encuentran ataques a vías de comunicación, contrabando, defraudación fiscal, narcotráfico y otros delitos contra la salud, portación ilegal de armas de fuego, lavado de dinero, tráfico de dinero, entre otros. Este tipo de delitos le corresponde a la Federación, son perseguidas por el Ministerio Público Federal, investigados por la Procuraduría General de la República y juzgados por el Poder Judicial Federal.

11. Un estudio sobre la inseguridad en México reveló que los estados más competitivos son los que tienen mayores capacidades institucionales y sociales para enfrentar la inseguridad, pero también son los que tienden a enfrentar mayor incidencia delictiva (González-Aréchiga, Hernández, Pérez Esparza, \& Weigend, 2012).

12. "Si no podemos resolver el problema en Monterrey, con todos los recursos y la gente que tenemos, pues eso es una preocupación sería para el resto de México", dijo Javier Astaburuaga, director de finanzas de la empresa Fomento Económico Mexicano FEMSA (Emmott, 2011).

13. Estado vecino de Nuevo León, ubicado al noreste del país.

14. Cámara de Comercio de México (CANACO) Confederación Patronal de la República Mexicana (COPARMEX), Cámara de la Industria de Transformación de Nuevo León (CAINTRA) y al Consejo Cívico de las Instituciones (CCINLAC). 
15. “El desplazamiento de poblaciones, la migración forzada, el éxodo y el exilio constituyen nuevas realidades para los habitantes de Tamaulipas y Nuevo León en el contexto de la guerra emprendida por el gobierno federal contra el narcotráfico y el crimen organizado" (Durin, 2012).

16. Según un estudio realizado por el Instituto Ciudadano de Estudios sobre Seguridad (2011), a causa de la inseguridad Nuevo León perdió 2.1\% de su Producto Interno Bruto en 2009.

17. Policías que se transportan en bicicleta con el propósito de fortalecer la seguridad pública y que sean ellos el primer vínculo con la ciudadanía.

18. Instrumento de rendición de cuentas con el que se mide, compara y comunica el nivel de cumplimiento de cada acción en cada ciudad del estado de Nuevo León.

19. Alfa es una empresa mexicana compuesta por cinco grupos de negocios: Alpek, Nemak, Sigma Alimentos, Alestra y Newpek.

20. CEMEX es una compañía global de soluciones para la industria de la construcción que ofrece productos y servicio a clientes y comunidades en más de 50 países en el mundo.

21. Soriana es una cadena mexicana de supermercados y almacenes.

22. Axtel es una empresa de telecomunicaciones que atiende todos los segmentos de mercado con una oferta de servicios integrales de comunicación.

23. Xignux es un consorcio industrial mexicano que participa en los mercados de cables y transformadores eléctricos, automotriz, petroquímico, iluminación, fundición, entre otros.

24. FEMSA es la compañía de bebidas más grande de Latinoamérica y la segunda más grande del sistema Coca-Cola en el mundo.

25. Alliax provee servicios de outsourcing en procesos administrativos, de nómina, capital humano, abastecimiento estratégico y tecnología de información.

26. A los pocos meses de que entró en operaciones Fuerza Civil, ya se encontraba entre las instituciones de mayor confianza entre la población, sólo detrás de la Marina, el Ejército y la Policía Federal (Pulso Metropolitano de Seguridad, 2013).

27. En septiembre de 2013 el Gobernador de Nuevo León dio a conocer en su cuenta de Twitter que Fuerza Civil ya contaba con 2,800 elementos en servicio y 690 en capacitación. Sin embargo, dijo que no se alcanzaría la meta sexenal prometida, que fue de 10,000 elementos al término de su Gobierno.

\section{REFERENCIAS}

Animal Político. (2011). En Monterrey, 92\% han cambiado al menos un hábito por inseguridad. Descargado de http://www.animalpolitico.com/2011/09/ 92-de-regiomontanos-han-cambiado-al-menos-un-habito-por-la-inseguridad/ \#axzz38iZJEh93

Banco Interamericano de Desarrollo (2007). Medellín: La transformación de una ciudad. Descargado de http://www.iadb.org/es/temas/seguridad-ciudadana/ impacto-medellin,5687.html 
Bartmanski, D. (2011). Successful icons of failed time: rethinking postcommunist nostalgia. Acta Sociologica, 54(3), 213-231.

Bourgeois, M., \& Verdoux, H. (1994). Duelo: clínica y patología. Enciclopedia Médica Chir. París Psychiatrie, 37-395.

Bowlby, J. (1983). The impact of death on the family system. Journal of Family Therapy, 5, 279-294.

Bridges, W. (1991). Managing transitions: Making the most of change. Boston: Da Capo Press Inc.

Bunce, V., \& Csanádi, M. (1993). Uncertainty in the transition: Post-communism in Hungary. East European Politics and Societies, 7, 240-275.

Calvet, R. (1996). Una tristeza que no engana. Revista Freudiana, 16, 57-68.

Canales, M. (2011). Los jóvenes del norte perdieron la noche. Revista Sin embargo. Descargado de http://www.sinembargo.mx/11-01-2013/486231

Carpenito, L. (1987). Diagnóstico de enfermería. Mexico: Interamericana.

CONEVAL. (2012). Medición de la pobreza en México y en las Entidades Federativas 2012. Descargado de http://www.coneval.gob.mx/Informes/Coordi nacion/Pobreza_2012/RESUMEN_EJECUTIVO_MEDICION_POBREZA_ 2012_Parte1.pdf

Constitución Política de los Estados Unidos Mexicanos. (1917). Artículos 21 y 115. Mexico D.F.: Diario Oficial de la Federación

DSM IV (1995). Manual diagnóstico y estadístico de los trastornos mentales. El Duelo. Barcelona: Masson.

Durin, S. (2012). La guerra que desplazó: familias del noreste de México en el exilio. Descargado de http://www.academia.edu/2553008/Los_que_la_guerra_ desplazo_familias_del_noreste_de_Mexico_en_el_exilio

El Economista. (2010). Queretaro participó con 1.9\% en el PIB nacional. Descargado de http://eleconomista.com.mx/estados/2011/12/05/queretaro-participo19-pib-nacional

Emmott, R. (2011). Si Monterrey se desploma, México se desploma. Descargado de http://mx.reuters.com/article/businessNews/idMXN0119154820110601? $\mathrm{sp}=$ true

Encuesta Nacional de Victimización y Percepción sobre Seguridad Pública (ENVIPE). (varios años). Descargado de http://www.inegi.org.mx/est/contenidos/pro yectos/encuestas/hogares/regulares/envipe/default.aspx

Encuesta Nacional sobre Inseguridad (ENSI). Descargado de http://www.inegi .org.mx/est/contenidos/proyectos/encuestas/hogares/especiales/ensi/default .aspx

Espinosa, R. (2009). Chilango no es gentilicio, es apodo. Milenio. Descargado de http://www.milenio.com/cdb/doc/impreso/8644309

Excelsior. (2011). Incendios a quienes no pagan extorsiones; calcinan dos negocios. Descargado de http://www.excelsior.com.mx/2011/08/31/nacional/765044

Fernandez Liria, A., \& Rodriguez Vega, B. (2002). Intervenciones sobre problemas relacionados con el duelo en situaciones de catastrofe, guerra o violencia politica. Revista de Psicoterapia, 13(49), 95-122.

Filgueira, M. (1995). Psicodrama focal del duelo patológico. SISO/SAUDE, 25, 17-32. 
Flores, O. (2011). Industria, comercio, banca y finanzas en Monterrey 1890-2000. Monterrey: UDEM. Descargado de http://issuu.com/oflores/docs/2.-flores-indus tria-completo1

Freud, S. (1917). Duelo y melancolía. In S. Freud (Ed.), Obras completas, Tomo XIV, Buenos Aires: Amorrortu Editores.

Fuerza Civil. (2013). Convertirse en fuerza civil. Gobierno del Estado de Nuevo León. Gobierno del Estado de Nuevo León. Descargado de http://www.fuerzacivil .org.mx

García, C., Fernández, M., \& Portales, L. (2011). Inseguridad, ¿freno al dinamismo económico en Nuevo León? XVI Congreso Internacional de Contaduría, Administración e Informática. UNAM. Descargado de http://congreso.investiga .fca.unam.mx/docs/anteriores/xvi/docs/10G.pdf

González-Aréchiga, B., Weigend, E., Pérez Esparza, D., \& Hernández Moreno, D. (2012). Índices sobre el entorno de inseguridad en los estados. EGAP: México.

Grollman, E. A. (1986). Vivir cuando un ser querido ha muerto. Barcelona: Ediciones 29.

Guerrero, E. La raíz de la violencia. Nexos. Descargado de http://www.nexos.com $. \mathrm{mx} / \mathrm{p}=14318$

Hernández, R. (2006). La sultana del norte también exporta mojados: reestructuración industrial y migración. In Ortega, I. (Coord.) El Noreste: Reflexiones. Monterrey: Fondo Editorial de Nuevo León.

ICESI. (2009). Instituto Ciudadano de Estudios sobre la Inseguridad. Descargado de http://www.seguridadcondemocracia.org/encuestas/estadisticas/cuader nos-del-icesi-2-indice-nacional-de-inseguridad.html

ICESI. (2012). ¿Corrupción o seguridad? Un estudio sobre la actual desconfianza en la policía mexicana. Descargado de http://new.pensamientopenal.com.ar/ sites/default/files/2012/04/ddhh02_0.pdf

IDB. (2009). Prólogo. In J. Orozco (Ed.) Monterrey, ciudad internacional del conocimiento (p. 7). Monterrey: Tecnológico de Monterrey.

IMCO. (2010). Nuevo León: Análisis de competitividad 2010. Descargado de http://imco.org.mx/indice_estatal_2010/PDFS/19.Nuevo_Leon.pdf

INEGI. (2010). Información por entidad. Nuevo León. Descargado de http:// cuentame.inegi.org.mx/monografias/informacion/nl/poblacion/default .aspx?tema $=$ me\&e $=19$

Instituto Ciudadano de Estudios sobre Seguridad. (2011). El costo de la inseguridad en México. Seguimiento 2009. Análisis de la ENSI-7. Descargado de http://www.culturadelalegalidad.org.mx/recursos/Contenidos/Procuracinde JusticiaySeguridadPbica/documentos/Costo \%20de\%20la\%20Inseguridad\%20 en\%20Mexico\%20-\%20ICESI\%202011.pdf

ITESM. (2012). Alcaldes y empresarios de Nuevo León visitaron Medellín y aprendieron de su proceso de transformación. Descargado de http://www.itesm .la/medellin/noticia/03-10-2012/alcaldes-y-empresarios-de-nuevo-leon-visita ron-medellin-y-aprendieron-de-su-proceso-de-transformacion

Kubler Ross, E. (1969). On death and dying: What the dying have to teach doctors, nurses, clergy and their own families. New York: Touchstone Books.

La Razón. (2010). Consulado de Estados Unidos da alerta en Monterrey. Descargado de http://www.razon.com.mx/spip.php?article28470 
Lafuente, M. J. (1996). Familia y muerte. In M. Millan (Ed.), Psicología de lafamilia: un enfoque evolutivo y sistémico (pp. 259-288).Valencia: Promolibro.

Lewin, K. (1947). Frontiers in group dynamics: Concept, method and reality in social science; social equilibria and social change. Human Relations, 1(1), 5-41.

Lorenzo, O. (2005). Nostalgia, shame and the transplanted Cuban: "la cubana arrepentida". Portal Journal of Multidisciplinary International Studies, 2(1). Descargado de http://epress.lib.uts.edu.au/journals/index.php/portal/article/view/78

Medellín, L. (2006). Las expectativas democráticas en el ascenso del PAN en Nuevo León. Biblioteca Jurídica Virtual del Instituto de Investigaciones Jurídicas de la UNAM. Descargado de http://biblio.juridicas.unam.mx/libros/6/2990/15.pdf

Mendieta, E. (2014). Medina reconoce deudas en desarrollo urbano. Milenio. Descargado de http://www.milenio.com/region/deuda_desarrollo_urbano-de sarrollo_urbano_Estado_0_307769338.html

Neimeyer R., Prigerson H., \& Davies, B. (2002). Duelo y significado. Revista de Psicoterapia, 13(49), 5-24.

Ortego, M. C., \& Alconero, A. R. (2001). El duelo. Enfermería Científica. Noviembre-Diciembre 2011, 46-51, 236-237.

Parkes, C. M. (1975). Bereavement: Studies of grief in adult life. London: Penguin.

Puig, T. (2009). Marca ciudad: cómo rediseñarla para asegurar un futuro espléndido para todos. España: Paidós.

Pulso Metropolitano de Seguridad. (2013). Boletín de Prensa, octubre de 2013. CAINTRA Nuevo Leon, el Consejo Civico, COPARMEX Nuevo Leon y el CIC. Descargado de http://cic.mx/wp-content/uploads/2013/10/Bolet\%C3\% ADn-de-prensa-pulsometro-septiembre-2013-confianza-en-autoridades.pdf

Pussetto, C., García, N., \& Pérez Esparza, D. (2008). Análisis de la ideología empresarial regiomontana. Descargado de http://redalyc.uaemex.mx/redalyc/src/ini cio/ArtPdfRed.jsp?iCve $=63340701 \#$

Rando, T. A. (1988). How to go on living when someone you love dies. New York: Bantam Books.

Revista Sin embargo. (2011). Nuevo León recurre a otros estados para reclutar a otros 8 mil policías. Descargado de http://www.sinembargo.mx/22-11-2011/79796

Rosenblatt, P., Walsh, P., \& Wackson, D. (1976). Grief and mourning in cross- cultural perspective. Indiana: HRAF Press.

Secretariado Ejecutivo del SNSP (2012). Acuerdo por el que se establecen los Lineamientos para el otorgamiento del subsidio a las entidades federativas para el fortalecimiento de sus instituciones de seguridad pública en materia de mando policial. Diario Oficial de la Federación. Descargado de http://dof.gob .mx/nota_detalle_popup.php?codigo $=523409$

SIPSE. (2011). Wikileaks: ligan a políticos regios con el narco. Descargado de http:// sipse.com/archivo/wikileaks-ligan-a-politicos-regios-con-el-narco-88420.html

Sistema Nacional de Seguridad Pública. (2013). Incidencia delictiva. Secretariado Ejecutivo. Información de Seguridad. Descargado de http://www.secretaria doejecutivosnsp.gob.mx/es/SecretariadoEjecutivo/Incidencia_Delictiva

Tapia, J. (2009). González Parás culpa a la Federación por el narco. Descargado de http://www.eluniversal.com.mx/notas/629353.html 
Tercer Sector. (2011). Nuevoleoneses ocupan tercera posición en cambio de hábitos, más de la mitad no usa joyas. Descargado de http://www.3ersector.mx/ index.php?option=com_content\&view=article\&id=2731:nuevoleoneses-ocu pan-tercera-posicion-en-cambio-de-habitos-mas-de-la-mitad-ya-no-usa-jo yas\&catid=2:2010

Torres, A. (2011). ITESM pierde $14.7 \%$ de matrícula por violencia. Descargado de http://eleconomista.com.mx/industrias/2011/05/09/itesm-pierde-147matricula-violencia

Valdes M., \& Blanco A. (1997). Reacciones de la familia después de la muerte de un ser querido: duelo, aflicción y luto. Actas Luso-Españolas de Neurología, Psiquiatría y Ciencias afines, 25(3), 190-196.

Vanguardia. (2011). En busca de la policía perdida. Descargado de http://www .vanguardia.com.mx/en_busca_de_la_policia_perdida-739390.html 